\title{
Currículo e avaliação: os testes estandardizados
}

\author{
Curriculum and assessment: standardized tests \\ Currículo y evaluación: las pruebas estandarizadas
}

\section{EDILENE ROCHA GUIMARÃES JOSÉ CARLOS MORGADO}

Resumo: O trabalho realiza um estudo comparado entre o ensino secundário em Portugal e o ensino médio no Brasil. Com metodologia qualitativa e o recurso à análise documental, objetiva-se analisar a relação entre currículo e avaliação, para compreender como os testes estandardizados têm conformado o currículo. Nos resultados averiguamos se os exames nacionais, organizados na base de lógicas de estandardização e uniformização e cuja regulação obedece a uma agenda globalizada, contribuem para estreitar o currículo nacional do ensino secundário/médio, confinando-o a uma lista de conteúdos e competências.

Palavras-chave: Currículo; avaliação; testes estandardizados.

\begin{abstract}
The paper makes a comparative study between secondary school in Portugal and high school in Brazil. With a qualitative methodology and the use of document analysis, it is aimed to analyze the relationship between curriculum and assessment to understand how standardized tests have conformed the curriculum. In the results it was examined whether the national tests, organized in logical base of standardization and uniformity and whose regulation follows a global agenda contribute to strengthening the national curriculum of secondary/ high school, restricting it to a list of content and skills.
\end{abstract}

Keywords: Curriculum; assessment; standardized tests.

Resumen: El trabajo hace un estudio comparativo entre la educación secundaria en Portugal y la escuela media en Brasil. La metodología cualitativa y el uso de análisis de documentos, con el fin de analizar la relación entre el currículo y evaluación para entender cómo las pruebas estandarizadas han dado forma al plan de estudios. Los resultados se examinaron si las pruebas nacionales, organizados en base lógica de la estandarización y la uniformidad y cuyo sigue una agenda global regulación contribuir a restringir el currículo nacional de la escuela secundaria / alta, confinarlo a una lista de contenidos y competencias.

Palabras clave: Currículo; evaluación; pruebas estandarizadas.

\section{INTRODUÇÃO}

Neste trabalho considera-se os novos modelos de governação como sendo de natureza pós-burocrática, de origem transnacional e supranacional, 
com efeitos nos processos e práticas sociais, incluídas as práticas educacionais (MAROY, 2012). Se a regulação burocrática tem como base a regra da conformidade, a legitimação pós-burocrática faz-se pela estandardização de resultados e normas, na base de uma regulação cognitiva, através das políticas de partilha de conhecimento, orientadas por organismos internacionais que impõem uma mudança conceitual, alimentada pelos conceitos relacionados à qualidade, competitividade, competência, eficiência e accountability (prestação de contas e responsabilização), entre outros (PACHECO; GUIMARÃES, 2013).

Compreende-se que os contextos dos sistemas de avaliação da educação relacionam-se com a qualidade da educação para a sua expansão. Como resultado dessa relação, configura-se a avaliação educacional enquanto ação pública para o seu controle, através de mecanismos de regulação centrados em dispositivos de accountability (LILLIS, 2012).

É nesse sentido que as reformas educativas que são realizadas em contextos sociais diferentes obedecem a uma mesma lógica de estandardização e uniformização, que se apresentam como as mais influentes da globalização (TAUBMAN, 2009). A perspetiva de redução da escola a números, indicam que sejam priorizados não só os resultados acadêmicos e a formação para o mercado de trabalho, mas também o disciplinamento para as rotinas escolares.

Os efeitos da globalização podem ser identificados na capilarização da cultura da performatividade nas políticas de currículo. Lopes e López (2010, p. $90,101)$ alerta que "a compreensão restrita do currículo como conteúdos a serem validados por sistemas de avaliação centrados nos resultados e os consequentes rankings de escolas e de alunos são apenas algumas das evidências públicas dos discursos produzidos por essa cultura". Através da cultura da performatividade e accountability os serviços sociais como a educação são "padronizados, calculados, qualificados e comparados, em uma dinâmica na qual os conhecimentos legitimados dos estudantes passam a ser vistos como idênticos aos resultados dos testes que o representam".

Segundo Afonso (2011, p. 88-89), "no quotidiano das instituições educacionais há sempre modos informais de accountability, mas são os sistemas formais que têm vindo a ganhar importância. Um sistema formal de accountability consiste em mensurar e codificar padrões de resultados e prever determinadas consequências quando se atingem ou não esses resultados". O autor afirma que é por esse motivo que a informação é crescentemente quantitativa e os métodos de mensuração são estandardizados. Esta formalização tem relações com a "emergência do chamado Estado-avaliador e com a disseminação de uma nova gestão pública (new publique manegement)" onde a definição prévia de objetivos de aprendizagem e sua mensuração e quantificação são aspectos centrais. É nesse 
sentido que algumas formas de accountability em educação têm sido estruturadas baseadas em resultados dos testes estandardizados no âmbito de avaliações externas.

A validade dos testes estandardizados como o Programm for International Student Assessment - PISA ${ }^{1}$, que avalia o ensino secundário, cujas bases são os rankings internacionais da educação, tem por aporte orientações conceitual e metodológica da educação comparada, que possibilitam evidenciar as orientações subjacentes a este tipo de avaliação padronizada e suas implicações políticas, como se articulam a um discurso internacional de competição econômica, de eficácia e eficiência e têm servido para a reorientação das políticas educativas.

A educação comparada constitui uma especialidade das Ciências da Educação, que permite a comparação e a aproximação de objetos de pesquisa da realidade educativa em diferentes contextos. Essa possibilidade tem contribuído para que a educação comparada recorra a novas epistemologias que permitem compreender a realidade educativa atual. Acresce o fato da especificidade deste campo o circunscrever ao "estudo de dois ou mais contextos educativos oriundos de diferentes espaços geográficos, com referências provenientes de autores a eles pertencentes". A descrição dos contextos e dos sistemas educativos é essencial para se realizar a comparação, "aproximando os objetos e buscando tanto as suas semelhanças quanto as diferenças” (REGNAULT, 2014, p. 14).

Compreendemos que a educação comparada contribui para um melhor entendimento dos fenômenos educativos em nível internacional, pois comparando os fatos e dados educativos de diferentes contextos, podemos melhor compreender a nossa própria cultura. A educação comparada, que tem por base o interculturalismo, é concebida como um espaço de compreensão da diversidade. Para Regnault (2014), a comparação está se tornando um "modo de governança", conceito amplamente utilizado nos meios políticos e científicos.

Como instrumento da educação comparada, a avaliação padronizada ou estandardizada é uma prática que vem sendo desenvolvida nos sistemas de ensino de diversos países. Antes a avaliação padronizada focava o pedagógico e suas medidas educacionais centravam-se no aluno, atualmente seu propósito relaciona o pedagógico com o político, tornando-se uma ferramenta de controle. Destacase que essa tendência tem caracterizado as políticas educativas desenvolvidas nos países membros da Organização para a Cooperação de Desenvolvimento Econômico (OCDE).

1 Para além do PISA, existem outros estudos estatísticos internacionais, como o Trends in International Mathematics and Science Study (TIMSS) ou o Progress in International Reading Literacy Study (PIRLS), cuja importância no âmbito da ação governativa lhes tem vindo a conferir o estatuto de tecnologia de governação. 
Assim, por meio da comparação internacional, pode-se avaliar o sistema educacional de determinado país em relação aos outros países e, desta maneira, verificar as deficiências e também a eficácia, muitas vezes não percebidas dentro dos próprios países, através dos seguintes indicadores: 1. Gasto Educacional por Estudante; 2. Gasto nas Instituições de Ensino relativo ao Produto Interno Bruto (PIB); 3. Investimento Público e Privado nas Instituições de Ensino; 4. Gasto Total em Educação; 5. Gasto nas Instituições de Ensino por Categoria de Serviços e Categoria por Natureza. Ou seja, consistem na comparação de indicadores entre os países da OCDE, quanto aos investimentos públicos em educação (http:// portal.inep.gov.br).

Em idêntica linha de pensamento, Guimarães, Pacheco, e Seabra (2013) esclarecem que pela força dos organismos transnacionais e supranacionais, as políticas educativas dos distintos países instauram, nos sistemas educativos nacionais, um certo grau de uniformidade não coerciva, de acordo com padrões moldados, por exemplo, pela União Europeia (EU), Banco Mundial (BM) e Organização para a Cooperação e Desenvolvimento Econômico (OCDE).

Em diversos países, tais políticas fizeram emergir um movimento de reforma baseado em standards (standards-based reform) que tem assumido o caráter de uma nova "ortodoxia" da mudança educativa (BOLÍVAR, 2007). A definição de standards ao determinar os conteúdos que os professores devem trabalhar nas aulas e o que os alunos devem aprender (objetivos de aprendizagem), através da avaliação externa com finalidades preestabelecidas, "se tem configurado como uma forma da tutela (re)centralizar os poderes de decisão educativa e curricular e de pressionar politicamente as escolas e os professores que nelas trabalham" (MORGADO, 2014, p. 139).

Assim, compreende-se que Guimarães e Pacheco (2014) afiancem que a avaliação padronizada tende a imprimir uma lógica e dinâmica organizacional, que se expressam no estímulo à competição entre as instituições educacionais e no seu interior, refletindo-se na forma de gestão, na perspectiva do fortalecimento dos mecanismos discriminatórios, e no currículo, no que se refere à possível "conformação aos testes de rendimento aplicados aos alunos, que tendem a ser vistos como os delimitadores do conhecimento que 'tem valor', entendido o conhecimento como o conjunto de informações a serem assimiladas pelos alunos e passíveis de testagem" (SOUSA, 2003, p. 187).

As políticas educativas, orientadas por agendas transnacionais, introduzem mecanismos de controle e regulação, próprios da produção e do mercado, no interior das instituições educacionais, com o objetivo de alcançar resultados educacionais que atendam às demandas e especificidades empresariais, no que se refere às lógicas do empreendedorismo, da produtividade e da relação forte 
entre escola e empresa. As estratégias utilizadas relacionam-se aos mecanismos de avaliação e controle, como forma de garantir que os "produtos educacionais" atendam aos estreitos e rígidos critérios do sistema produtivo globalizado (GUIMARÃES; PACHECO, 2014).

Diante dos contextos dos sistemas de avaliação da educação em Portugal e no Brasil, considera-se que as políticas curriculares interagem com as políticas avaliativas, de forma a estruturar estratégias de conformação dos currículos do ensino secundário/médio, apresentando novas perspetivas de definição das políticas educativas para esse nível de ensino.

Este trabalho resulta de um estudo comparado entre o ensino secundário em Portugal e o ensino médio no Brasil, com o objetivo de analisar a relação entre currículo e avaliação, tentando compreender como é que os testes estandardizados têm conformado o currículo.

Tendo como base dados empíricos sobre os testes avaliativos do ensino secundário em Portugal e do ensino médio no Brasil, cujo corpus foi constituído pelos principais documentos que definem as políticas curriculares e avaliativas, seguimos uma metodologia qualitativa, com o intuito de analisar a relação entre currículo e avaliação, tentando compreender como é que os testes estandardizados têm conformado o currículo. Na análise documental, a principal técnica de tratamento dos dados utilizada foi a análise de conteúdo, baseando-se nos procedimentos de Bardin (1979) e considerando o modo como é analisada por Esteves (2006).

\section{CONTEXTOS DA AVALIAÇÃO EM PORTUGAL E NO BRASIL}

A avaliação do ensino secundário em Portugal e do ensino médio no Brasil situa-se em contextos educativos e curriculares que não se distanciam significativamente, "sobretudo se forem analisadas as semelhanças que existem pela via das políticas de partilha de conhecimento e pelo predomínio do modelo pós-burocrático na governação” (PACHECO; GUIMARÃES, 2013, p. 4).

Em Portugal, a avaliação no ensino secundário tem sido realizada com base no currículo nacional, através de dois tipos de exames nacionais: exames para o cálculo da classificação final no ensino secundário e exames para acesso ao Ensino Superior. Nesse processo (sobre)valorizam-se os exames e os resultados obtidos, uma vez que condicionam quer o currículo que se desenvolve nas escolas, quer o prosseguimento de estudos, quer, ainda, a entrada no mercado de trabalho. No primeiro caso, no cálculo da classificação final no ensino secundário, embora existam duas modalidades de avaliação legalmente previstas - a avaliação formativa e a avaliação sumativa -, prevalece a modalidade sumativa, dado o peso que 
assume no final deste nível de ensino. Idealizada como um juízo globalizante, que permite tomar decisões sobre a classificação e aprovação em cada disciplina, área não disciplinar e módulos, interferindo, assim, na progressão em disciplinas não terminais e na transição para os anos de escolaridade subsequentes, a avaliação sumativa é determinante na conclusão e certificação dos alunos que frequentam, e concluem, o ensino secundário.

A preponderância da avaliação sumativa, cujos instrumentos privilegiados são os testes escritos e os exames nacionais, é ainda reforçada pelo fato de ao longo do ensino secundário se sistematizar em avaliação sumativa interna - integrada no processo de ensino-aprendizagem e formalizada em reuniões do conselho de turma no final dos $1^{\circ}, 2 .^{\circ}$ e terceiro períodos letivos ou concretizada através de provas de equivalência à frequência, realizadas no final dos anos terminais (PORTUGAL, 2015) - e avaliação sumativa externa - destinando-se, neste caso, a aferir o grau de desenvolvimento das aprendizagens dos estudantes, recorrendo, para o efeito, à utilização de instrumentos definidos a nível macro e à realização de exames finais nacionais.

No segundo caso, relativo ao acesso ao Ensino Superior, a candidatura a esse nível de ensino pressupõe a satisfação de duas condições prévias: (i) ser portador de um curso do ensino secundário - ou de habilitação legalmente equivalente; (ii) ter realizado, com êxito, os exames nacionais de ingresso - específicos para diferentes cursos e instituições (PORTUGAL, 2014a). Convém lembrar que existem instituições que, para além dos aspetos referidos, exigem que se cumpram determinados pré-requisitos de natureza física, vocacional ou funcional, sem os quais não permitem a frequência de determinados cursos que integram a sua oferta educativa (idem) - como é o caso dos cursos da área da Educação Física / Desporto e da Licenciatura em Educação Básica, nomeadamente a variante em Educação Musical.

O regime de acesso ao Ensino Superior prevê, ainda, de acordo com o estipulado no Decreto-Lei no 393-A/1999, de 2 de outubro ${ }^{2}$, a existência de Regimes Especiais de candidaturas para estudantes em condições específicas como, por exemplo, os estudantes que se encontrem em Missão Diplomática ou Oficial no Estrangeiro, os Oficiais das Forças Armadas, os Bolseiros dos PALOP (Países Africanos de Língua Oficial Portuguesa), os Praticantes Desportivos de Alto Rendimento, entre outros - e a existência de Concursos Especiais, regulados pelo Decreto-Lei no 113/2014, de 16 de julho ${ }^{3}$, como é o caso do Concurso

2 O Decreto-Lei n ${ }^{\circ} 393-A / 99$, de 2 de outubro, regula os Regimes Especiais de Acesso e Ingresso no Ensino Superior.

3 O Decreto-Lei $n^{\circ} 113 / 2014$, de 16 de julho, institui e regulamenta os concursos especiais para Acesso e Ingresso no Ensino Superior.

378 - RBPAE - v. 32, n. 2, p. 373 - 392 mai./ago. 2016 
Especial para maiores de 23 anos, o Concurso Especial para titulares de Diploma de Técnico Superior Profissional ou de Diploma de Especialização Tecnológica ou o Concurso Especial para Acesso ao Curso de Medicina por titulares de grau de licenciado, neste caso previsto pelo Decreto-Lei no 40/2007, de 20 de fevereiro ${ }^{4}$.

Em qualquer dos casos referidos (sobre)valorizam-se os exames e os resultados obtidos, uma vez que condicionam quer o currículo que se desenvolve nas escolas e que garante o prosseguimento de estudos, quer nos programas de acesso ao Concursos Especiais de Acesso e Ingresso ao Ensino Superior, quer, ainda, na obtenção de habilitações acadêmicas e profissionais necessárias para a consequênte entrada no mercado de trabalho.

Destaca-se o Decreto-Lei $n^{\circ} 17 / 2016$, de 4 de abril, que foi publicado numa lógica de mudança do paradigma avaliativo em Portugal $1^{5}$, levada a efeito pelo Governo que iniciou funções em 2016, acaba por reafirmar a importância dos exames finais nacionais, ao reiterar que têm como objetivo avaliar o desempenho dos alunos e certificar a conclusão do ensino secundário nas ofertas formativas que prevejam avaliação externa das aprendizagens, podendo ainda ser considerados para efeitos de acesso ao ensino superior. Não suscita dúvidas de que (sobre) valorização dos exames interfere no modo como se concebe e operacionaliza o currículo que se desenvolve nas escolas.

No Brasil, em 1998, o governo federal criou o Exame Nacional do Ensino Médio (ENEM) como instrumento para avaliar o desempenho dos estudantes ao final da educação básica.

Durante mais de dez anos o ENEM foi utilizado para avaliar as habilidades e competências de concluintes do ensino médio, sem o objetivo de selecionar para o ensino superior. "Os exames de seleção, os concursos vestibular ao ensino superior, eram formulados por equipes locais país afora e formatos diferentes ocorriam nas diversas universidades. Da heterogeneidade entre os distintos concursos decorria certa diversidade cultural e de formação dos ingressantes no ensino superior” (SILVEIRA, BARBOSA; SILVA, 2015, p. 1101-1).

Até 2008, o ENEM era uma prova clássica com 63 questões interdisciplinares e uma redação sem a possibilidade de comparação das notas de um ano para outro. A proposta para 2009 do governo federal apoiada pela Associação Nacional dos Dirigentes das Instituições Federais de Ensino Superior

4 O Decreto-lei no $40 / 2007$, de 20 de fevereiro, institui e regula um concurso especial para acesso ao curso de Medicina por titulares do grau de licenciado.

5 O Decreto-Lei n ${ }^{\circ}$ 17/2016, de 4 de abril, que estabelece os princípios orientadores da organização e da gestão dos currículos dos ensinos básico e secundário, da avaliação dos conhecimentos a adquirir e das capacidades a desenvolver pelos alunos e do processo de desenvolvimento do currículo dos ensinos básico e secundário. 
(ANDIFES), era reformular o ENEM para que o exame pudesse ser comparável no tempo e abordasse diretamente o currículo do ensino médio.

Em maio de 2009, o Ministério da Educação (MEC) apresentou uma proposta de reformulação do Exame Nacional do Ensino Médio (ENEM) e sua utilização como forma de seleção unificada nos processos seletivos das universidades públicas federais, através do Sistema de Seleção Unificada (SiSU). O SiSU foi implantado como um sistema informatizado gerenciado pelo MEC, no qual as Instituições Federais de Educação Superior (IFES) oferecem vagas para candidatos participantes do ENEM.

O ENEM associado ao SiSU tem como principais objetivos democratizar as oportunidades de acesso às vagas federais de ensino superior, possibilitar a mobilidade acadêmica e induzir a reestruturação dos currículos do ensino médio. Estruturado a partir de uma matriz de habilidades e um conjunto de conteúdos associados a elas, o ENEM passou a ser composto por quatro testes, um por cada área do conhecimento, a saber: (i) Linguagens, Códigos e suas Tecnologias (incluindo redação); (ii) Ciências Humanas e suas Tecnologias; (iii) Ciências da Natureza e suas Tecnologias; e (iv) Matemática e suas Tecnologias. Cada grupo de testes foi composto por 45 itens de múltipla escolha, aplicados em dois dias.

Esta estrutura aproximou o ENEM das Diretrizes Curriculares Nacionais Gerais para a Educação Básica e do currículo praticado nas escolas, sem abandonar o modelo de avaliação centrado nas competências e habilidades. Importa, ainda, referir que as Diretrizes Curriculares Nacionais para o Ensino Médio, instituídas pela Resolução CNE/CEB no 2/2012, determinam que o currículo do ensino médio deve contemplar as mesmas quatro áreas do conhecimento, ainda que com um tratamento metodológico que incida na contextualização e na interdisciplinaridade (BRASIL, 2012).

Em relação ao conjunto de conteúdo, o exame passou a ser construído em parceria com a comunidade acadêmica das Instituições Federais de Educação Superior (IFES), através de uma Matriz de Referência, "os objetos de conhecimento associados poderão ser aprimorados, nas edições seguintes do ENEM, de modo a consagrar o papel do Exame de orientar a melhoria do Ensino Médio em harmonia com os processos de seleção para o acesso à Educação Superior" (BRASIL, 2009a, p.1).

Destaca-se a participação das IFES como protagonistas no processo de repensar o ensino médio, "discutindo a relação entre conteúdos exigidos para ingresso na educação superior e habilidades que seriam fundamentais, tanto para o desempenho acadêmico futuro, quanto para a formação humana" (BRASIL, 2009b, p. 3) 
De acordo com o discurso oficial, diferentemente dos modelos e processos avaliativos tradicionais, a prova do ENEM é interdisciplinar e contextualizada, coloca o estudante diante de situações-problemas, exigindo que mais do que saber conceitos, o estudante saiba aplicá-los.

A partir de 2009, ações governamentais estimularam o uso do ENEM não apenas como um processo de avaliação do ensino médio, mas como forma de acesso ao ensino superior no Brasil, cuja programação inicial de aplicação do exame foi de: inscrições em julho, realização das provas em outubro e divulgação dos resultados em dezembro. O Sistema de Seleção Unificada (SiSU), a partir de sua $1^{\text {a }}$ Edição em janeiro de 2010, passou a operar em larga escala no processo de alocação dos candidatos às vagas das IFES.

Salienta-se que o ENEM permite ao participante do exame obter o Certificado de Conclusão do Ensino Médio, observando os seguintes requisitos: a) possuir 18 (dezoito) anos completos até a data da realização da primeira prova do ENEM; b) atingir o mínimo de 450 (quatrocentos e cinquenta) pontos em cada uma das áreas do conhecimento; c) atingir o mínimo de 500 (quinhentos) pontos na redação.

O ENEM tem como meta, também, possibilitar a participação em programas governamentais de acesso ao ensino superior, como o Programa Universidade para Todos (ProUni), que utiliza os resultados do exame como prérequisito para a distribuição de bolsas de estudo a alunos egressos do ensino médio da rede pública ou da rede particular na condição de bolsistas integrais, com renda familiar per capita máxima de três salários mínimos, em instituições ensino superior privadas.

O ENEM, também, permite a participação no Fundo de Financiamento Estudantil (FIES), que é um programa do Ministério da Educação que financia cursos superiores não gratuitos e com avaliação positiva no Sistema Nacional de Avaliação da Educação Superior (SINAES).

Destaca-se que o ENEM, a partir de 2009, possibilitou o estabelecimento de uma relação direta entre o currículo do ensino médio e as habilidades e conteúdos exigidos para ingresso na educação superior, por meio de um debate com a comunidade acadêmica das IFES, focado nas diretrizes da prova.

O ENEM possibilitou, ainda, oferecer uma referência para autoavaliação com vistas a auxiliar nas escolhas futuras dos cidadãos, tanto com relação à continuidade dos estudos quanto à sua inclusão no mundo do trabalho, sendo considerado como complemento do currículo para a seleção de emprego.

Denota-se dessa discussão que tanto em Portugal como no Brasil os exames nacionais, organizados na base de lógicas de estandardização e uniformização e cuja regulação obedece a uma agenda globalizada, têm contribuído para estreitar 
o currículo nacional do ensino secundário/médio, confinando-o a uma lista de conteúdos e competências.

\section{INFLUÊNCIAS DA AVALIAÇÃO NO CURRÍCULO}

A pesquisadora Alice Casimiro Lopes afirma que no Brasil "as escolas tendem a se pautar pelo que é cobrado nos exames independentemente da clareza ou não dos documentos curriculares", denotando as influências da avaliação no currículo. "Se o sucesso da escola, dos professores e dos alunos tende a ser vinculado aos resultados nos exames, os exames se tornam um poderoso instrumento de constituição de uma base nacional" e um preponderante fator de controle pessoal e profissional (http://revistaeducacao.uol.com.br/textos).

Em Portugal, o panorama tem sido idêntico, sobretudo desde a última "revisão" [diríamos reforma] da estrutura curricular do ensino básico e secundário, com os reflexos que essas mudanças produziram ao nível do acesso ao Ensino Superior. Ainda que a tutela tenha garantido tratar-se apenas da revisão da estrutura curricular, com introdução de ajustes pontuais, os normativos publicados e as medidas aprovadas e postas em prática permitem-nos afirmar que, "de forma velada", se tratou mais de uma reforma do que de uma revisão, não só pela (re)organização estrutural que implicou mas também pelos valores e pelos efeitos que essas medidas, "de cariz essencialmente técnico e imobilista", geraram (MORGADO, 2013, pp. 226-227).

Um desses efeitos diz respeito ao facto de os decisores políticos, com o pretexto de conferir maior rigor à avaliação, terem procedido à introdução de exames nacionais no final do $4^{\circ}, 6^{\circ}$ e $9^{\circ}$ ano de escolaridade e de revalorizarem o papel dessas provas no percurso e no sucesso educativos dos alunos (idem). Aliás, a afirmação de que os exames permitiriam consignar maior rigor à avaliação não deixa, desde logo, de revelar uma clara desconfiança no trabalho dos professores, com reflexos ao nível da sua autonomia profissional. Uma autonomia que, apesar de relativa, é mais congruente com outras formas de avaliação, como por exemplo a avaliação formativa, quando reunidas as condições efetivas para a sua realização. Torna-se desnecessário e contraproducente invocar a necessidade de induzir maior rigor através de avaliações externas, quando o próprio Estado tem legitimidade para as utilizar como meios de controle ou como instrumentos de recolha de informação sobre o sistema educativo e as escolas que tutela.

Mas, o que está em jogo é bem diferente e muito mais preocupante do que aquilo que se difunde pelos discursos. Trata-se de criar condições para que, de forma análoga ao que se passa noutros países, se implementem reformas baseadas 
em standards (standards-based reform) ${ }^{6}$, dando corpo a um movimento que, na opinião de Bolívar (2007, p. 24), tem vindo a assumir "o carácter de uma nova 'ortodoxia' da mudança educativa". Trata-se de uma situação preocupante, se tivermos em conta que o recurso a standards determina os conteúdos que os professores devem trabalhar nas aulas e o que os alunos devem aprender, escrutinando a posteriori, através da avaliação externa (exames nacionais, avaliação institucional, avaliação do desempenho docente) a consecução, ou não, das metas preestabelecidas. Em síntese, um meio propício para o Ministério da Educação (re)centralizar poderes para pressionar politicamente as escolas e os professores que nelas trabalham.

Embora as reformas baseadas em standards possam provocar mudanças na relação entre as políticas (educativas e curriculares) e as práticas docentes, podendo mesmo gerar efeitos positivos, concordamos com Pacheco (2007) quando assegura que aquilo que se tem verificado é que essas mudanças têm contribuído, essencialmente, para que os contextos de ensino se configurem como produtores de "identidades técnicas", uma vez que se procura avaliar e responsabilizar os professores mais pelo lado dos resultados dos alunos do que pelo seu lado mais pessoal e de gestão dos processos de aprendizagem.

Em idêntica linha de pensamento, Robinson (2011, p. 236) reconhece que a educação tem sido "persistentemente estrangulada pela cultura dos testes padronizados", embora sem efeitos palpáveis em termos qualitativos. Considera que essa situação tem sido favorecida pela falta de rigor avaliativo que existe nas escolas, tanto ao nível das estratégias de ensino como dos processos avaliativos, e pela oposição entre a avaliação formativa e a avaliação sumativa. Para Robinson, esse impasse só poderá ser resolvido se a avaliação se concretizar através das duas modalidades, se nutrir de maior rigor e se cada escola assumir a autoavaliação de processos e resultados como meio de melhorar o serviço educativo que oferece. É que, quando essas premissas se concretizam, as instituições tornam-se menos vulneráveis a imposições externas e mais imunes à afirmação de lógicas de controle externo.

Importa, ainda, referir, a propósito da crescente centralidade dos exames nacionais e dos testes estandardizados nos processos avaliativos em Portugal, que tais artefatos, para além de se revelarem meios propícios para legitimar normativamente o currículo e para controlar curricularmente os professores, sobretudo através das tão propaladas prestação de contas e responsabilizaçãa, são uma forma de burocratizar o fenômeno educativo e empobrecer [ou trivializar] o

6 Andy Hargreaves e Dean Fink (2007, p. 21) designam este movimento como "movimento da reforma educativa e dos padrões de desempenho [standards]", esclarecendo que se funda nas ideias de que "a aprendizagem tem prioridade sobre o ensino" e de sabermos "quando é que essa aprendizagem ocorre efetivamente". 
currículo que se desenvolve nas escolas, uma vez que, de forma mais ou menos explícita, condicionam o que aí deve ser ensinado e/ou aprendido.

Destaca-se que, em Portugal, à semelhança do que se passa em outros contextos, os testes estandardizados e os exames nacionais favorecem o recurso a processos de aprendizagem memorísticos ou de recuperação de informação, bem como a reprodução do conhecimento acadêmico, necessário para progredir ao longo de um nível ou ciclo de ensino. Uma situação preocupante se tivermos em conta que tal conhecimento pouco tem a ver com os saberes que os estudantes utilizam na sua vida quotidiana para compreender as situações em que participam e elaborar propostas de ação.

No Relatório do Conselho Nacional de Educação - Estado da Educação 2014 - afirma que nas escolas que têm "resultados médios de avaliação externa mais baixos aumenta o diferencial entre estes e os resultados médios de classificação interna, diminuindo em escolas cujos resultados médios de avaliação externa são mais elevados". Esta tendência permite demonstrar a influência que a avaliação produz ao nível do currículo, uma vez que "configura, por um lado, a existência de inflação de classificações perante alunos com desempenhos mais baixos, e, por outro, a eventual aplicação de níveis de exigência excessivos mediante grupos de alunos de desempenho mais elevado". Além disso, tende a fazer com que os processos de ensino-aprendizagem se centrem mais nos resultados do que, como seria desejável, nos processos que o permitem obter. O fato dos testes estandardizados ou os exames nacionais tenderem a "estrangular" o fenômeno educativo não impediu que no ensino secundário tenha ocorrido uma clara “diminuição das taxas de retenção e desistência desde 2011/2012” (PORTUGAL, 2014b, p. 212).

No Brasil a situação é referida como sendo distinta, uma vez que se afirma que os testes estandardizados e os exames nacionais favorecem o recurso a processos de aprendizagem que desenvolvem a compreensão e a contextualização do conhecimento acadêmico. Entretanto, a ausência de uma Base Nacional Comum Curricular (BNCC) tem levado a avaliação de larga escala, como o Exame Nacional do Ensino Médio (ENEM), a ser utilizada como matriz da base curricular, principalmente quando atrelada às políticas de responsabilização (accountability), com publicação de rankings e promoção de bônus às escolas bem escalonadas.

Para compreender as influências da avaliação no currículo diante da ausência da BNCC, tomamos como base o Plano Nacional de Educação - PNE 2014-2024, Lei no 13.005, de 25 de junho de 2014, em sua Meta 3, referente a universalização do Ensino Médio (BRASIL, 2014). 
A Meta 3 assume dois objetivos principais para efetivar o direito à educação e ampliar os níveis de acesso para os jovens entre 15 e 17 anos: i) elevar o percentual dos que frequentam a escola, de forma a incluir $100 \%$ dessa população até o ano de 2016; ii) aumentar para 85\%, até 2024, o total dos jovens cursando o ensino médio (EM), que é o percentual considerado pelo PNE adequado para a faixa etária. O alcance dos objetivos da Meta 3 relaciona-se com a melhoria do atendimento e da taxa de conclusão na idade adequada no ensino fundamental, pois a expansão da oferta do ensino médio depende da ampliação dos índices de conclusão nessa etapa anterior (BRASIL, 2015).

No Brasil, conforme "Observatório do PNE", cerca de 2,9 milhões de crianças e jovens de 4 a 17 anos estão fora da escola. Desses, aproximadamente 1,6 milhão são jovens de 15 a 17 anos que deveriam cursar o ensino médio. $\mathrm{O}$ desafio da universalização até 2016 do atendimento escolar, regulamentado pela Emenda Constitucional no 59/2009, parece inatingível, pois cerca de 83,3\% dos jovens entre 15 a 17 anos estão na escola, e apenas 59,5\% desses jovens estão matriculados no ensino médio (http://www.observatoriodopne.org.br).

O Instituto Nacional de Estudos e Pesquisas Educacionais Anísio Teixeira (INEP), com dados estatísticos dos Censos da Educação Básica de 2014-2010, mostra que o número total de matrículas no ensino médio sofreu um decréscimo de 57.486 matrículas neste período e que a oferta se encontra concentrada em áreas urbanas na rede pública estadual (http://portal.inep.gov.br).

Entendemos que muitos jovens de 15 a 17 anos encontram-se fora da escola por existir outras opções de Certificação do Ensino Médio, que tem provocado o decréscimo do número de matrículas, como é o caso do Exame Nacional do Ensino Médio (ENEM) como entidade certificadora. Ou seja, o ENEM tem substituído o próprio ensino médio, através da certificação para o estudante que possuir 18 anos de idade ou mais e conseguir, no mínimo, 450 pontos em cada uma das quatro áreas de conhecimento das provas (Linguagens; Matemática; Ciências da Natureza; Ciências Humanas) e 500 pontos na redação.

As elevadas taxas de evasão observadas no decréscimo de matrícula têm dificultado atingir os objetivos da Meta 3 do PNE 2014-2024. Destaca-se que o currículo tem sido considerado como um dos fatores determinantes da evasão escolar, principalmente por se apresentar fragmentado com elevado número de disciplinas e conteúdos descontextualizados, o que torna o ensino médio sem significado para a maioria dos jovens de 15 a 17 anos. Além do que, a Certificação do Ensino Médio com base no resultado do ENEM tem provocado a evasão dos estudantes que completam 18 anos de idade e não concluíram a educação básica.

A Meta 3 dispõe de 14 Estratégias. Visando reformular o currículo do ensino médio, a Estratégia 3.2. determina que o Ministério da Educação (MEC), 
“em articulação e colaboração com os entes federados e ouvida a sociedade mediante consulta pública nacional, elaborará e encaminhará ao Conselho Nacional de Educação - CNE, até o $2^{\circ}$ (segundo) ano de vigência deste PNE", ou seja, até junho de 2016, "proposta de direitos e objetivos de aprendizagem e desenvolvimento para os (as) alunos (as) de ensino médio, a serem atingidos nos tempos e etapas de organização deste nível de ensino, com vistas a garantir formação básica comum". A Estratégia 3.3. define "a implantação dos direitos e objetivos de aprendizagem e desenvolvimento que configurarão a base nacional comum curricular do ensino médio" (compondo 60\% do currículo do ensino médio). Enquanto que a Estratégia 3.6. indica as influências da avaliação no currículo, ao definir a universalização do Exame Nacional do Ensino Médio ENEM, fundamentado em matriz de referência do conteúdo curricular do ensino médio, que permita promover sua utilização como instrumento de avaliação sistêmica, certificadora e classificatória (BRASIL, 2014).

Visando cumprir o que foi regulamentado pelo PNE (2014-2024), o MEC colocou em consulta pública, no período de 25/09/2015 a 15/03/2016, a Minuta da Base Nacional Comum Curricular (http://basenacionalcomum.mec. gov.br). Em entrevista o Ministro da Educação, Renato Janine Ribeiro, afirmou que "no ensino médio, a Base Comum tem que dialogar com o ENEM. A tendência de todo o sistema educacional há muito tempo é que o ensino médio seja telegovernado pelo acesso à universidade" (http://g1.globo.com/educacao/ noticia).

\section{A NECESSIDADE DE VALORIZAR A DIVERSIDADE DE CONTEXTOS E DAS IDENTIDADES DAS INSTITUIÇÕES EDUCATIVAS}

A valorização da diversidade de contextos e das identidades das instituições educativas põe em questão as políticas universalistas, que nos leva a considerar a cultura como área substantiva e não simplesmente como elemento de homogeneização da sociedade (HALL, 2003). As políticas de universalização do acesso à educação básica atingem "diferencialmente diversos grupos e temas que reclamam o direito à diversidade e a inclusão e, é identificada pela sociedade que reivindica direito diferenciado e esse acesso, bem como demarca a necessidade de representação no âmbito educacional” (SILVA, 2009, p. 92-93).

$\mathrm{Na}$ perspetiva do direito à diversidade e inclusão, o currículo vem sendo considerado como uma realidade em constante elaboração, voltada para as grandes questões contemporâneas: identidade, diferença, sustentabilidade, meio ambiente, género, etnia, raça, multiculturalismo, sexualidade, inclusão, 
globalização das ideias, volatilidade das informações, saber/poder, entre outras (DIAS, MACHADO; NUNES, 2009).

Diante dessas questões contemporâneas, identifica-se algumas linhas de evolução na política educativa a nível internacional que são incorporadas nos diversos sistemas educativos: a) o reconhecimento da inadequação de currículos uniformes, de sistemas educativos centralistas e rigidamente organizados; b) a necessidade de reforço do papel decisor das escolas no plano curricular e organizacional; c) a necessidade de diferenciação curricular quer no campo da organização dos conteúdos de aprendizagem, quer dos processos e métodos de ensino (ROLDÃO, 2000, pp. 127-128).

Em idêntica linha de pensamento, Young (2010) adverte para se considerar no desenvolvimento curricular a preocupação com "o que ensinar" em diversos contextos. Essa perspectiva remete às reflexões acerca das práticas curriculares como processos de diversificação e diferenciação curricular, em contraposição aos testes estandardizados que têm produzido a homogeneização da cultura escolar. Segundo Guimarães e Pacheco (2012, p. 68), o conceito de diversificação curricular relaciona-se com formas organizacionais de ofertas educativas, como tipos diferentes de cursos, de ensino, e modalidades de formação, nas quais os alunos são confrontados com percursos escolares diferentes, na perspectiva de currículos alternativos. A diversificação curricular relaciona-se à reorganização das situações de aprendizagem face às capacidades, interesses e motivações dos alunos, mantendo uma base nacional curricular com objetivos e conteúdos a que todos os alunos devem aceder. Já o conceito de diferenciação curricular representa, "para além de alterações no conteúdo, mudanças na metodologia e na avaliação, pressupondo que os alunos têm um mesmo percurso nas suas opções, mas que uns precisam seguir caminhos diferentes para que todos possam atingir o sucesso educativo".

Os projetos pedagógicos das instituições educativas devem ser considerados como um documento que "elaborado com a participação da comunidade educativa, estabelece a identidade própria de cada escola através da adequação do quadro legal em vigor à sua situação concreta, apresenta o modelo geral de organização e os objectivos pretendidos pela instituição e, enquanto instrumento de gestão, é ponto de referência orientador na coerência e unidade da acção educativa" (COSTA, 1991, p. 10).

Com essa compreensão, salienta-se a necessidade de valorizar a diversidade de contextos e das identidades das instituições educativas, na construção das políticas avaliativas e das políticas curriculares, no que se refere à interação com os projetos pedagógicos das instituições educativas. 


\section{CONSIDERAÇÕES FINAIS: PARA ALÉM DOS TESTES ESTANDARDIZADOS}

Para além dos testes estandardizados, com o sentido de valorizar a diversidade dos contextos dos sistemas de ensino e das identidades das instituições educativas, concluímos que há uma interação entre as políticas avaliativas e as políticas curriculares, de forma que os testes estandardizados utilizados para a avaliação final da educação básica têm estruturado estratégias de conformação dos currículos do ensino secundário em Portugal e do ensino médio no Brasil, os quais interferem na construção autônoma dos projetos pedagógicos das instituições educativas, devido ao atendimento dos requisitos impostos pelos instrumentos avaliativos, exercendo um controle direto sobre os conteúdos curriculares e processos de avaliação realizados nas escolas, com vistas a construir as habilidades e conteúdos exigidos ao ingresso nos cursos superiores, que são previamente definidos pelas Instituições de Educação Superior.

Entendemos que independentemente das transformações que a política educativa possa introduzir nos Sistemas de Ensino, é fundamental a capacidade dos professores perfilharem uma visão mais democrática e democratizante do processo avaliativo, uma vez que deles depende em grande parte o(s) sentido(s) que a avaliação assume.

\section{REFERÊNCIAS}

AFONSO, A. J. Questões polêmicas no debate sobre políticas educativas contemporâneas: o caso da accountability baseada em testes estandardizados e rankings escolares. In: ALVES, M. P.; KETELE, J. de (Orgs.). Do currículo à avaliação, da avaliação ao currículo. Porto: Porto Editora, 2011, p. 83-101.

BARDIN, L. Análise de Conteúdo. Lisboa: Edições 70, 1979.

BOLÍVAR, A. Um olhar actual sobre a mudança educativa: onde situar os esforços de melhoria? In: LEITE, C.; LOPES, A. (Orgs.), Escola, currículo e formação de identidades. Porto: Edições Asa, 2007, p. 13-50.

BRASIL. Plano Nacional de Educação PNE 2014-2024: Linha de Base. Brasília: INEP/MEC. 2015.

BRASIL. Lei no 13.005, de 25 de junho. Aprova o Plano Nacional de Educação PNE e dá outras providências. Brasilia: Presidência da República, 2014. 
BRASIL. Resolução $\mathbf{n}^{\mathbf{o}}$ 2, de 30 de janeiro. Define Diretrizes Curriculares Nacionais para o Ensino Médio. Brasília: MEC/CNE/CEB, 2012.

BRASIL. Matriz de Referência do ENEM 2009. Brasília: INEP/MEC/ ANDIFES, 2009a.

BRASIL. Proposta à Associação Nacional dos Dirigentes das Instituições Federais de Ensino Superior. Brasília: INEP/MEC, 2009b.

COSTA, J. Gestão escolar - participação, autonomia, projeto educativo. Lisboa: Texto Editora, 1991.

PORTUGAL. Avaliação no ensino secundário em Portugal. Lisboa: MEC/ DGE, 2015.

PORTUGAL. Concurso Nacional de Acesso ao Ensino Superior Público. Lisboa: MEC/ DGES, 2014a.

PORTUGAL. Estado da Educação 2014. Lisboa: CNE, 2014b.

DIAS, A. A.; MACHADO, C. J. S.; NUNES, M. L. S. Currículo, formação docente e diversidades socioculturais. In: DIAS, A. A.; MACHADO, C. J. S.; NUNES, M. L. S. (Orgs.). Educação, Direitos Humanos e Inclusão: currículo, formação docente e diversidades socioculturais. João Pessoa, Editora Universitária da UFPB, 2009, p. 09-25.

ESTEVES, M. Análise de conteúdo. In: LIMA, J. A.; PACHECO, J. A. (Orgs.), Fazer investigação. Contributos para a elaboração de dissertações e teses. Porto: Porto Editora, 2006, p. 105-126.

GUIMARÃES, E. R.; PACHECO, J. A. Sistema de Avaliação da Educação Superior em Portugal e no Brasil e sua influência no currículo. Atas do XI Colóquio / VII Colóquio Luso-Brasileiro / I Colóquio Luso-Afro-Brasileiro de Currículo. Braga, 2014, p. 3553-3562.

GUIMARÃES, E. R.; PACHECO, J. A. Projeto Educativo TEIP. Um estudo de caso. Revista Portuguesa de Investigação Educacional, v. 11, 65-88, 2012. 
GUimarÃES, E. R.; PACHECO, J. A.; SEABRA, F. Políticas de educação profissional em Portugal e no Brasil. RBPAE - v. 29, n. 3, set/dez, 557-574, 2013.

HALL, S. Da diáspora: identidades e mediações culturais. Belo Horizonte, Editora da UFMG, 2003.

LILLIS, D. Systematically evaluating the effectiveness of quality assurance programmes in leading to improvements in institutional performance. Quality in Higher Education, 18 (1), 59-73, 2012.

LOPES, A. C.; LÓPEZ, S. B. A Performatividade nas políticas de currículo: o caso do ENEM. Educação em Revista. Belo Horizonte, v.26, n. 01, abr., 89110, 2010.

MAROY, C. Towards post-bureaucratic modes of governance. An European perspective. In: STEINER-KHAMSI, G.; WALDOW, F. (Eds.). World yearbook of education 2012. Policy borrowing and lending in education. London: Routledge, 2012, p. 62-93.

MORGADO, J. C. (Des)propósitos da atual revisão curricular em Portugal. In: FAVACHO, M.; PACHECO, J. A.; SALES, S. R. (Orgs.). Currículo, Conhecimento e Avaliação: divergências e tensões. Curitiba, Brasil: Editora CRV, 2013, p. 221-237.

MORGADO, J. C. Currículo, identidade e profissionalidade docente: desafios contemporâneos. In: MORGADO, J. C.; QUITEMBO, A. D. (Orgs.). Currículo, avalição e inovação em Angola. Perspectivas e desafios. ONDJIRI EDITORES, Banguela - Angola, 2014, p. 129-154.

PACHECO, J. A. Políticas educativas e curriculares: para uma análise do contexto português. In: SOUSA, J. M. (Org.). Educação para o sucesso: políticas e actores. Atas do IX Congresso da SPCE. Funchal: Universidade da Madeira, 2007, p. 159-168.

PACHECO, J. A.; GUIMARÃES, E. R. A escola como máquina de integração social. Um estudo sobre as realidades brasileira e portuguesa a partir das políticas e práticas educativas e curriculares. Acta Científica - XXIX Congreso de la Asociación Latinoamericana de Sociología, Santiago: ALAS, 2013. 
REGNAULT, E. Validade dos rankings internacionais baseados nos testes: PIRLS, PISA e Shanghai. RBPAE - v. 30, n. 1, jan/abr, 13-40, 2014.

ROBINSON, K. O Elemento. Porto: Porto Editora, 2011.

ROLDÃO, M. C. A Problemática da diferenciação curricular no contexto das políticas educativas actuais. In: ROLDÃO, M. C.; MARQUES, R. (Orgs.). Inovação, currículo e formação. Porto: Porto Editora, 2000, 121-133.

SILVA, J. M. M. A Curricularização da diversidade. In DIAS, A. A.; MACHADO, C. J. S.; NUNES, M. L. S. (Orgs.). Educação, Direitos Humanos e Inclusão: currículo, formação docente e diversidades socioculturais. João Pessoa: Editora Universitária da UFPB, 2009, p. 85-98.

SILVEIRA, F. L.; BARBOSA, M. C. B. B.; SILVA, R. Exame Nacional do Ensino Médio (ENEM): uma análise crítica. Revista Brasileira de Ensino de Física, v. 37, n. 1, 1101, 1-5, 2015.

SOUSA, S. M. Z. L. Possíveis impactos das políticas de avaliação no currículo escolar. Cadernos de Pesquisa, n. 119, 175-190, 2003.

TAUBMAN, P. Teaching by numbers. Deconstructing the discourse of standards and accountability in education. London: Routledge, 2009.

YOUNG, M. Conhecimento e currículo: do socioconstrutivismo ao realismo social na sociologia da educação. Adaptação para a língua portuguesa de Jorge Ávila de Lima. Porto: Porto Editora, 2010.

EDILENE ROCHA GUIMARÃES é doutora em educação pela Universidade Federal de Pernambuco com estágio de pós-doutoramento na Universidade do Minho, Portugal. É professora no Instituto Federal de Educação, Ciência e Tecnologia de Pernambuco (IFPE), Brasil. Líder do Grupo de Pesquisa Formação Integral e Cidadania (IFPE/CNPq). E-mail: edilene.guimaraes@recife.ifpe.edu.br

JOSÉ CARLOS MORGADO é doutor em Educação, especialidade de Desenvolvimento Curricular, pela Universidade do Minho, em Braga - Portugal. É professor no Instituto de Educação da mesma Universidade (IE-UM), Diretor 
do Departamento de Estudos Curriculares e Tecnologia Educativa (DECTE) e Investigador no Centro de Investigação em Educação (CIEd). E-mail: jmorgado@ie.uminho.pt

Recebido em maio de 2016

Aprovado em junho de 2016 